\title{
AVALIAÇÃO FÍSICO-QUÍMICA E SENSORIAL DE DIFERENTES MELADOS
}

\author{
Pedro Paulo Augusto Fabiano Arantes Pereira Barreto ${ }^{1}$, Silvia Raquel Bettani ${ }^{2}$, Maria Teresa \\ Mendes Ribeiro Borges ${ }^{2}$, Marta Regina Verruma-Bernardi ${ }^{2}$ \\ ${ }^{1}$ Centro de Biologia Molecular e Engenharia Genética (CBMEG) - UNICAMP, E-mail: pedropbarretto@gmail.com \\ 22Universidade Federal de São Carlos, E-mail: raquelbettani@gmail.com, mtmrborg@cca.ufscar.br, verruma@cca.ufscar.br
}

\section{RESUMO}

Este trabalho teve como objetivo analisar as características físico-químicas e sensoriais de melados produzidos por inversão: enzimática, ácida, natural e sem inversão, comparados com melado comercial. Os parâmetros físico-químicos analisados incluíram cinzas, açúcar redutor, açúcar redutor total, $\mathrm{pH}$, acidez e sólidos solúveis. Os melados diferiram em todos os atributos sensoriais demonstrando a heterogeneidade das amostras. Os resultados do teste de aceitação mostraram que os melados provenientes de inversão ácida apresentaram aceitação próxima ao melado comercial, e o melado sem inversão foi o menos aceito.

Palavras-chave: Cor, melado, sensorial

\section{PHYSICO-CHEMICAL AND SENSORY EVALUATION OF DIFFERENT MOLASSES}

\section{ABSTRACT}

This study aimed to analyze the physico-chemical and sensory characteristics of sugarcane molasses produced by enzymatic, acidic and natural inversion and without inversion compared to a commercial molasses. The physico-chemical parameters analyzed included ashes, reducing sugar, total reducing sugar, $\mathrm{pH}$, acidity and soluble solids. Sensory analysis consisted of quantitative descriptive analysis (QDA) and acceptance testing. Sugarcane molasses differed in all sensorial attributes demonstrating the heterogeneity of the samples. Acceptance test show that the sugarcane molasses from acidic inversion presented results near to the commercial molasses acceptance and molasses without inversion was less appreciated.

Keywords: Color, molasses, sensory

\section{INTRODUÇÃO}

Segundo Brasil (1978) o melado é o líquido xaroposo obtido pela evaporação do caldo de cana-de-açúcar ou a partir da dissolução da rapadura, por processos tecnológicos adequados.

O melado é obtido em pequenas quantidades, na grande maioria de forma 
artesanal em propriedades onde trabalham famílias de agricultores. Representa um estágio já remoto da industrialização da cana-de-açúcar, e em sua fabricação, de maneira geral, não são empregados procedimentos de higienização do caldo, de controle da qualidade do produto nem tão pouco do processo (DELGADO \& DELGADO, 1999).

Suas características sensoriais são: aspecto líquido xaroposo e denso (viscoso), cor amarelo âmbar, com aroma e sabor próprios e gosto doce. Em relação a características físico-químicas, o melado pode apresentar um máximo de $25 \% \mathrm{~m} / \mathrm{m}$ (massa/massa) de umidade, acidez máxima de $10 \mathrm{mg} .100 \mathrm{~mL}^{-1}$, glicídios totais um mínimo de $50 \% \mathrm{~m} / \mathrm{m}$ e no máximo $6 \% \mathrm{~m} / \mathrm{m}$ de resíduo mineral fixo (cinzas) (Brasil, 1978).

O melado, do ponto de vista nutricional, apresenta muitos minerais e vitaminas presentes, provenientes do caldo, como cálcio, ferro, fósforo, magnésio, potássio, vitamina $\mathrm{A}$ e vitaminas do complexo $\mathrm{B}\left(\mathrm{B}_{1}, \mathrm{~B}_{2}, \mathrm{~B}_{5}\right.$ e $\left.\mathrm{B}_{6}\right)$ (BELITZ, 1993).

Contudo, para um produto de boa qualidade ser obtido, com aspecto visual atraente, recomenda-se a inversão de parte da sacarose presente, para que não ocorra a cristalização da mesma, seguido de um tratamento do caldo, de forma similar ao realizado na produção de açúcar mascavo, porém, com adição de cal em menor quantidade, de forma que o pH final não seja superior a 6. A inversão deve ser apenas parcial, pois a sacarose confere aos produtos sabor e textura característicos, os quais devem ser mantidos, tanto quanto possível. A inversão parcial da sacarose dá origem à frutose e à glicose, monossacarídeos que não cristalizam durante o armazenamento (LOPES \& BORGES, 1998).

A cristalização, ou "açucaramento", é um dos maiores problemas referentes à qualidade do melado, fazendo com que este apresente uma menor vida de prateleira, além de perder suas características físicoquímicas e sensoriais. Para que esse processo de cristalização seja evitado, a sacarose deve ser hidrolisada até que se atinja um nível mínimo de $25 \%$ de açúcares redutores (DELGADO \& DELGADO, 1999).

A hidrólise da sacarose, para a produção de melado, pode ser realizada de três formas: natural, ácida e enzimática. $\mathrm{Na}$ inversão natural, é utilizado o caldo de cana cru, já que este apresenta enzimas e leveduras em sua constituição. A maior parte da produção de melado atualmente baseia-se 
nessa técnica de inversão. Os pequenos produtores para produzirem o melado aguardam alguns dias para que a cana cortada e armazenada sofra inversão da sacarose pelo processo da deterioração natural dos colmos. No entanto, por não ser controlada, esta prática pode acarretar na síntese de compostos de degradação, os quais proporcionam, muitas vezes, aroma desagradável, prejudicando a qualidade do melado (LOPES \& BORGES, 1998).

A inversão ácida utiliza, de preferência, ácidos orgânicos como o cítrico e o ascórbico. Estes ácidos podem ser adicionados ao caldo de cana, o qual é aquecido até ebulição para inversão e concentração, culminando na obtenção do melado (LOPES \& BORGES, 1998).

Com relação à inversão enzimática, a Invertase (E.C. 3.2.1.26) é a principal enzima utilizada na indústria alimentícia para a hidrólise da sacarose (VICENTE, 2000; DAVID, 2004). No entanto, as enzimas são compostos altamente susceptíveis à desnaturação em função do $\mathrm{pH}$ e temperatura, tornando os trabalhos com estes compostos extremamente difíceis de controlar.

Deste modo, o trabalho teve como objetivo analisar as características físicoquímicas e sensoriais de melados produzidos por inversão enzimática, ácida e natural e sem inversão, comparando-os com um melado comercial.

\section{MATERIAL E MÉTODOS}

O caldo utilizado foi proveniente de cana-de-açúcar, variedade RB72454, e foi extraído em moenda garapeira convencional, partindo de um peso bruto de aproximadamente, $100 \mathrm{~kg}$, dos quais foram retirados $50 \mathrm{~L}$ de caldo para a produção de melado.

Este caldo foi dividido em cinco porções de $10 \mathrm{~L}$, sendo subdivididos em 2 amostras de $5 \mathrm{~L}$, para a realização do experimento em duplicata, onde procederam-se os seguintes tratamentos: (A) inversão enzimática, (B) inversão com ácido cítrico, (C) inversão com lima ácida, (D) inversão natural, (E) sem inversão. Para avaliação final dos melados produzidos incluiu-se, também, uma amostra de melado comercial (F).

O caldo foi evaporado até, aproximadamente, o teor de sólidos solúveis de $75^{\circ}$ Brix, medidos em refratômetro digital.

A inversão enzimática (A) ocorreu utilizando a enzima Invertase Industrial (E.C.3.2.1.26) a uma concentração de 0,5 g. $L^{-1}$ de caldo de cana-de-açúcar durante 30 
minutos, com temperatura controlada em torno de $55^{\circ}$ C. A enzima utilizada apresentava atividade específica de 2700

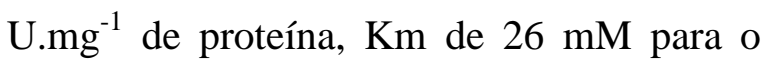
substrato utilizado (sacarose), e pH ótimo de 5,5, que condiz com o pH natural do caldo.

A inversão ácida (amostra B) ocorreu utilizando ácido cítrico e foi utilizado $10 \mathrm{~g} . \mathrm{L}^{-}$ 1 de ácido cítrico $\left(\mathrm{pK}_{\mathrm{a}}=3.25\right)$, para $\mathrm{a}$ inversão da sacarose do caldo, o qual permaneceu em repousou durante 20 minutos.

A inversão ácida (C) foi realizada com uso de suco de lima ácida 'Tahiti', utilizando-se uma quantidade equivalente à $10 \mathrm{~g}$ de ácido cítrico por litro de caldo. Esta equivalência foi obtida através de titulação ácido-base do suco da fruta. $\mathrm{O}$ caldo permaneceu em repouso por 20 minutos.

A inversão natural da sacarose (D) ocorreu por meio das enzimas endógenas, sendo que, para isso, o caldo foi deixado em repouso por aproximadamente 18 horas. O caldo sem inversão (E) foi extraído, evaporado e concentrado até a consistência de xarope e o tratamento $(F)$ trata-se de um melado comercial. Os melados produzidos foram resfriados, envasados e armazenados em temperatura ambiente.

Foram analisados os seguintes parâmetros: cinzas condutimétricas (\%), açúcar redutor (\%), açúcar redutor total (\%), $\mathrm{pH}$, acidez (mg ácido acéticol $100 \mathrm{~mL}$ ), sólidos solúveis $\left({ }^{\circ}\right.$ Brix). Todas as metodologias seguiram as recomendações da International Commission for Uniform Methods of Sugar Analysis-ICUMSA (2011) e foram realizadas no Laboratório de Análises e Simulação Tecnológica (LAST) do Departamento de Tecnologia Agroindustrial e Sócio-Economia Rural do Centro de Ciências Agrárias da UFSCar. As análises foram realizadas em triplicata.

Para a análise sensorial dos melados foi utilizado o método da Análise Descritiva Quantitativa (ADQ), descrito por Stone \& Sidel (1993), e os testes realizados das 9 às $11 \mathrm{~h}$ e das 14 às 16h, no Laboratório de Análise Sensorial do CCA/UFSCar, com a participação de 14 julgadores préselecionados, levando-se em consideração o interesse e a disponibilidade dos mesmos.

Cerca de $20 \mathrm{~mL}$ de melado foram servidos à temperatura ambiente, codificados com números aleatórios de três dígitos. $\mathrm{O}$ levantamento de atributos foi realizado utilizando o método Rede, descrito por Kelly (1955), citado por Moskowitz (1983).

Após o levantamento de atributos e discussão dos termos sensoriais, foi gerada uma lista de termos descritivos com as definições e respectivos extremos da cada 
escala. Durante o treinamento, os julgadores foram solicitados a avaliar a intensidade de cada atributo sensorial das amostras dos melados utilizando escala não estruturada de $9 \mathrm{~cm}$, ancorada nos extremos.

Utilizando o critério para seleção de julgadores em função da habilidade de discriminar as amostras e repetir resultados nas avaliações, não foi excluído nenhum provador, pois nenhum apresentou probabilidade de $\mathrm{F}_{\text {amostras }}$ não significativo $(\mathrm{p} \geq 0,05)$, ou $\mathrm{F}_{\text {repetição }}$ significativo $(\mathrm{p} \leq 0,05)$ (DAMÁSIO \& COSTELL, 1991). A lista dos atributos com as respectivas definições está apresentada na Tabela 1.

Tabela 1. Atributos sensoriais de melado e suas respectivas definições (Araras, 2013).

\begin{tabular}{|c|c|}
\hline Atributos & Definiçõos \\
\hline Aparência viscosa & $\begin{array}{l}\text { Refere-se ao deslizamento com recipiente } \\
\text { inclinado durante três segundos. }\end{array}$ \\
\hline \multirow[t]{3}{*}{ Cor amarela } & $\begin{array}{l}\text { Refere-se a cor característica de açúcar } \\
\text { caramelizado. }\end{array}$ \\
\hline & Claro: Karo®. \\
\hline & Escuro: melado de cana Hemmer®. \\
\hline \multirow[t]{3}{*}{ Aroma doce } & Refere-se ao aroma doce. \\
\hline & Fraco: calda de pêssego. \\
\hline & Forte: caramelo. \\
\hline \multirow[t]{3}{*}{ Aroma rapadura } & Refere-se ao aroma de rapadura. \\
\hline & Fraco: garapa. \\
\hline & Forte: rapadura. \\
\hline \multirow[t]{3}{*}{ Sabor doce } & Refere-se ao sabor doce. \\
\hline & Fraco: garapa. \\
\hline & Forte: rapadura. \\
\hline \multirow[t]{3}{*}{ Sabor ácido } & Refere-se a ácido. \\
\hline & Nenhum: ausência de acidez. \\
\hline & Muito: limão. \\
\hline Textura viscosa & $\begin{array}{l}\text { Refere-se à permanência na boca por mais } \\
\text { tempo. }\end{array}$ \\
\hline
\end{tabular}


As amostras foram avaliadas em relação à aparência, aroma, sabor e textura, em escala não estruturada, apresentadas monadicamente, em ordem balanceada. Os testes foram realizados em cabines individuais visando manter o isolamento de cada provador, em triplicata. Os julgadores utilizaram água mineral para lavar o palato entre uma amostra e outra.

Foi realizado um teste de aceitação global, utilizando-se escala hedônica de sete pontos variando de "desgostei muito" (1 ponto) a "gostei muito" (7 pontos). Trinta consumidores participaram do teste, os quais receberam cerca de $20 \mathrm{~mL}$ de cada melado, codificados.

Os resultados da análise sensorial foram submetidos à análise de variância (ANOVA) utilizando o programa estatístico SAS (2003) e as diferenças entre as médias $(\mathrm{p} \leq 0,05)$ comparadas através do teste de Tukey.

Para os resultados da analises físicoquímicos foram realizados medias de três repetições.

\section{RESULTADOS E DISCUSSÃO}

Os resultados das análises físicoquímicas estão apresentados na Tabela 2.

Observou-se que os teores de sólidos solúveis variaram entre $71^{\circ}$ Brix (E) para o melado sem inversão e $82^{\circ}$ Brix $(\mathrm{F})$ para o melado comercial. Lopes \& Borges (1998) relatam que o valor deve ficar entre 75 a $82^{\circ}$ Brix, enquanto Delgado \& Delgado (1999) estipula o valor entre 74 a $78^{\circ}$ Brix. Brasil (1978) relata que o teor de sólidos solúveis do melado está entre 50 e $74^{\circ}$ Brix. Melados com teor de sólidos solúveis na faixa de 75 ${ }^{\circ}$ Brix são mais fluidos facilitando a homogeneização em escala industrial, assim como apresentam certa resistência a deterioração microbiológica quando comparados aos melados de concentrações inferiores a $65^{\circ}$ Brix, em função de alta pressão osmótica. Já melados com teor de sólidos solúveis na faixa de $82^{\circ}$ Brix apresentam textura atrativa para usos à mesa. Percebe-se que a proposta de Lopes \& Borges (2004) é mais flexível e abrangente, atendendo a indústria de alimentos, e ao consumo direto na mesa.

O teor de açúcares redutores (AR) é muito importante para esse tipo de produto, quanto maior esse teor, maior a garantia de que o produto não sofrerá cristalização. Lopes \& Borges (1998) e Delgado \& Delgado (1999) indicam que o valor mínimo para açúcares redutores deve ser próximo de 25 g. $100 \mathrm{~g}^{-1}$ de melado, ou seja, $25 \%$ do produto deve ser composto por glicose e 
frutose. No entanto os resultados da Tabela 1 mostram uma variabilidade muito grande (14 a 40,1\%) neste parâmetro. Segundo a proposta, três melados atingiram o teor sugerido para AR, respectivamente e em ordem crescente os tratamentos: Inversão Enzimática (28,7\%), Inversão Natural $(38,8 \%)$ e Inversão com lima ácida $(40,8 \%)$ e próximo a $25 \%$ a amostra Comercial com $21,60 \%$ de AR.

As amostras de melados produzidos com inversão por ácido cítrico (14\%) e sem inversão $(15,2 \%)$ encontra-se totalmente fora deste padrão proposto.
Na legislação (BRASIL, 1978) não há informação sobre o teor de açúcares redutores (AR) deste produto, este parâmetro é sugerido como sendo uma forma de garantir um aumento na vida de prateleira do mesmo, sem que sejam alteradas as características principalmente visuais do produto.

Outro atributo importante na designação do produto é o ART (açúcares redutores totais), que representam os glicídios totais.

Tabela 2. Resultados* obtidos nas análises físico-químicas dos melados obtidos por diferentes tratamentos (Araras, 2013).

\begin{tabular}{|c|c|c|c|c|c|c|c|}
\hline Melado & Tratamentos & ${ }^{\circ}$ Brix* & $\begin{array}{c}\mathbf{A R} \\
(\%)^{*}\end{array}$ & $\begin{array}{l}\text { ART } \\
(\%)^{*}\end{array}$ & pH & $\begin{array}{c}\text { Acidez } \\
(\mathrm{mg} / 100 \mathrm{~mL})\end{array}$ & $\begin{array}{c}\text { Cinzas } \\
(\%)\end{array}$ \\
\hline A & Inv. enzimática & 75,30 & 28,70 & 61,90 & 6,20 & 3,10 & 1,84 \\
\hline B & Inv.ác.cítrico & 75,40 & 14,00 & 65,84 & 4,32 & 17,50 & 1,31 \\
\hline $\mathrm{C}$ & Inv. lima ácida & 79,00 & 40,80 & 58,16 & 4,36 & 16,40 & 1,38 \\
\hline $\mathrm{D}$ & Natural & 78,80 & 38,80 & 68,80 & 5,02 & 5,80 & 1,21 \\
\hline $\mathrm{E}$ & Sem inversão & 71,00 & 15,20 & 52,20 & 6,01 & 2,10 & 1,26 \\
\hline F & Comercial & 82,00 & 21,60 & 60,80 & 6,50 & 3,20 & 2,08 \\
\hline
\end{tabular}


Esse atributo está relacionado com a soma dos açúcares presentes (sacarose, glicose e frutose). A legislação brasileira (BRASIL, 1978) estabelece que a porcentagem mínima de glicídios no melado deve ser 50\%. Desta maneira todos os melados apresentam valores adequados a legislação vigente.

Com relação ao $\mathrm{pH}$ e acidez, os melados invertidos a partir de ácido cítrico e lima ácida obtiveram maiores valores para acidez e menores para $\mathrm{pH}$, e não se adequaram à legislação, que estipula uma acidez máxima de $10 \mathrm{mg} \cdot 100 \mathrm{~mL}^{-1}$. A legislação ainda não prevê a produção de melado com ácido cítrico ou lima ácida. Os demais melados produzidos no estudo, bem como, o comercial se adequaram a legislação, apresentando valores de acidez na faixa de 2,1 a $5,8 \mathrm{mg} .100 \mathrm{~mL}^{-1}$ e $\mathrm{pH}$ entre 5,02 a 6,50 .

Em relação ao teor de sais minerais, todos os melados apresentaram-se adequados a legislação vigente, ficando abaixo do teor estipulado como máximo permitido $(6 \%$ $\mathrm{m} / \mathrm{m})$.

Os atributos sensoriais que descreveram os melados foram para aparência: viscosa e cor; aroma: doce, de rapadura; textura: viscosidade; sabor: sabor doce e ácido (Tabelas 3 e 4).
Quanto à aparência viscosa (Tabela 3), a escala foi definida analisando o deslizamento do produto sobre superfície inclinada durante aproximadamente três segundos, sendo que a escala variou de pouco viscoso a muito viscoso. O principal fator a ser levado em conta quando é analisada a viscosidade do melado é o teor de sólidos solúveis. Se uma amostra apresenta sólidos solúveis elevados, ela consequentemente vai ser mais viscosa, o que de fato foi visto pelos julgadores, já que a amostra mais viscosa foi a comercial, obtendo um valor superior a 7, e tendo Brix de $82^{\circ}$.

A cor das amostras de melado foi avaliada no intervalo "amarela clara a amarela escura" (Tabela 3) e verificou-se que as amostras A, D e E foram as mais escuras, ou seja, se aproximaram mais da cor da amostra Controle - Comercial. As amostras B e C foram as mais claras, provavelmente pelo fato de o ácido ser um produto que clarifica o caldo de cana-deaçúcar (LOPES, 2011).

Quanto a textura viscosa (Tabela 3) a amostra com inversão enzimática (A) obteve-se maior media $(6,87)$ seguida das $\operatorname{amostras} \mathrm{D}, \mathrm{B}$ e $\mathrm{A}(\mathrm{p} \geq 0,05)$ e as amostras C e E com menor média para textura viscosa. O atributo textura viscosa é um atributo 
fortemente ligado ao teor de sólidos solúveis, mostrando que os maiores teores, foram as amostras que permaneceram por mais tempo na boca. Se compararmos nas Tabelas 2 e 3 verifica-se que a amostra $F$ possui o maior teor de sólidos solúveis, consequentemente com maior viscosidade descrita pelos julgadores.

Segundo Delgado \& Delgado (1999) o aroma doce do melado é uma de suas principais características sensoriais, sendo considerado uma característica referente a qualidade do produto, tendo em vista o consumidor.

Quanto à definição dos atributos, a característica aroma doce, variou de "fraco a forte" (Tabela 4). Nesses atributos os melados se dividiram em 2 grupos, sendo 4 deles considerados muito doces (acima de 4,5) e 2 deles considerados pouco doces (abaixo de 4,5). O aroma doce é um atributo que se refere principalmente ao teor de sólidos solúveis e de açúcares redutores, que são mais doces do que a sacarose, portanto um melado com ${ }^{\circ}$ Brix e teor de açucares redutores maior, provavelmente terá um aroma mais doce que os demais (DELGADO \& DELGADO, 1999). Quanto ao aroma de rapadura (Tabela 4), a amostra E apresentouse mais intensa para este atributo e a amostra B o mais fraco. Apenas 2 das 6 amostras de melado se mostraram com um aroma de rapadura intenso, sendo que uma delas é a amostra sem inversão (E), que cristalizou, mostrando que esse atributo não é muito presente nas amostras de melado produzidas por outros métodos. As outras 4 amostras obtiveram médias menores que 4,5, o que representa um aroma de rapadura fraco, mostrando que essa característica não é esperada no melado.

Os atributos mostrados são importantes para qualidade do produto $\mathrm{e}$ preferência do consumidor, e apresentam resultados bem variáveis. Como no caso do sabor doce, em que as amostras A, D e F obtiveram resultados semelhantes, sem diferença significativa. As amostras B e C apresentaram sabor menos doce e valores maiores para sabor acido. Quanto ao sabor ácido, as amostras invertidas com ácido (B e C) se apresentaram mais ácidas sensorialmente (acima de 4,5), enquanto as outras 4 amostras permaneceram com características de sabor pouco ácidas. A amostra menos ácida foi a invertida com enzima, mostrando a pouca interferência desse tipo de inversão na acidez do produto, e mostrando também, que o produto originado desse tipo de inversão, nesse atributo, é o que menos foge das características tradicionais. 
Tabela 3. Médias dos atributos de aparência, aroma e textura nas amostras de melado (Araras, 2013).

\begin{tabular}{lccc}
\hline Amostras & Viscosidade aparente & Cor & Textura viscosa \\
& & & \\
\hline A (enzimática) & $3,34 \mathrm{c}$ & $5,91 \mathrm{a}$ & $4,33 \mathrm{~b}$ \\
B (ácido cítrico) & $6,16 \mathrm{ab}$ & $3,05 \mathrm{~b}$ & $4,57 \mathrm{~b}$ \\
C (lima ácida) & $3,51 \mathrm{c}$ & $3,56 \mathrm{bc}$ & $2,85 \mathrm{c}$ \\
D (natural) & $5,97 \mathrm{~b}$ & $5,96 \mathrm{a}$ & $5,13 \mathrm{~b}$ \\
E (sem inversão) & $2,00 \mathrm{a}$ & $5,05 \mathrm{a}$ & $2,57 \mathrm{c}$ \\
F (comercial) & $7,23 \mathrm{a}$ & $4,85 \mathrm{ab}$ & $6,87 \mathrm{a}$ \\
\hline DMS* & 1,1204 & 1,3829 & 1,341 \\
\hline
\end{tabular}

Médias na vertical com letras diferentes implica em diferença significativa $(\mathrm{p} \leq 0,05)$.

Tabela 4. Médias dos atributos de aroma e sabor nas amostras de melado (Araras, 2013).

\begin{tabular}{lcccc}
\hline Amostras & Aroma doce & Aroma de & Sabor doce & Sabor \\
& & rapadura & & ácido \\
\hline A (enzimática) & $4,45 \mathrm{a}$ & $3,69 \mathrm{bc}$ & $5,84 \mathrm{a}$ & $2,51 \mathrm{c}$ \\
B (acido cítrico) & $2,71 \mathrm{~b}$ & $2,16 \mathrm{~d}$ & $2,56 \mathrm{c}$ & $6,65 \mathrm{a}$ \\
C (lima ácida) & $4,92 \mathrm{a}$ & $3,59 \mathrm{c}$ & $3,52 \mathrm{bc}$ & $6,04 \mathrm{a}$ \\
D (natural) & $4,79 \mathrm{a}$ & $4,98 \mathrm{ab}$ & $6,17 \mathrm{a}$ & $3,96 \mathrm{~b}$ \\
E (sem inversão) & $2,72 \mathrm{~b}$ & $5,47 \mathrm{a}$ & $4,39 \mathrm{~b}$ & $3,42 \mathrm{bc}$ \\
F (comercial) & $4,80 \mathrm{a}$ & $3,40 \mathrm{~cd}$ & $6,33 \mathrm{a}$ & $2,81 \mathrm{bc}$ \\
\hline DMS & 1,397 & 1,3225 & 1,1923 & 1,2906 \\
\hline
\end{tabular}

Média na vertical com letras diferentes implica em diferença significativa $(\mathrm{p} \leq 0,05)$.

Os resultados das análises de estatística das amostras D e B. A melhor aceitação estão apresentados na Tabela 5. O média foi para amostra comercial porém sem melado sem inversão $-\mathrm{E}$ foi $\mathrm{o}$ que diferença significativa para as amostras $\mathrm{C}$ e apresentou as piores médias entre as A. amostras analisadas, porém sem diferença 
Tabela 5. Médias das notas obtidas para aceitação global dos melados (Araras, 2013).

\begin{tabular}{ll}
\hline Amostras & Notas \\
\hline A (enzimática) & $3,3 \mathrm{bc}$ \\
B (acido cítrico) & $3,5 \mathrm{abc}$ \\
C (lima ácida) & $4,2 \mathrm{ab}$ \\
D (natural) & $3,3 \mathrm{bc}$ \\
E (sem inversão) & $2,5 \mathrm{c}$ \\
F (comercial) & $4,4 \mathrm{a}$
\end{tabular}

Médias na vertical com letras diferentes implica em diferença significativa $(\mathrm{p} \leq 0,05)$.

\section{CONCLUSÕES}

Os melados produzidos apresentaram características físico-químicas distintas devido principalmente as formas de obtenção, contudo em sua maioria atenderam a legislação brasileira e a literatura quanto aos parâmetros de qualidade do produto.

Em relação a aceitação pelo consumidor, os melados que foram invertidos por via ácida ficaram com os níveis de aceitação mais próximos do melado comercial contrapondo o melado sem inversão que obteve a menor aceitação.

\section{REFERÊNCIAS BIBLIOGRÁFICAS}

BRASIL. 1978. Resolução 12/33 de 1978 da Comissão Nacional de Normas e Padrões para Alimentos. Normatização brasileira relativa a açúcar mascavo, melado e rapadura. Disponível em: <http://www.panelamonitor.org/media/do crepo/document/files/normatizacaobrasileira-relativa-a-acucar-mascavomelado-e-rapadura.pdf $>$. Acesso em: 20 de Set. 2013.

BELITZ, H.D. 1991. Química dos alimentos, Zaragoza: Acribia, 737 p.

DAMÁSIO, M.H.; COSTELL, E. 1991. Análisis sensorial descriptivo: generación de descriptores y selección de catadores. Revista Agroquimica y Tecnologia de Alimentos, Valencia, v.31, n.2, p.165178.

DAVID, A.E. 2004. Immobilization of enzymes in nanoporus silica composites. Tese (Doutorado) Universidade de Maryland, College Park, Maryland.

DELGADO, A.A; DELGADO, A.P. 1999. Produção do açúcar mascavo, rapadura e melado, Piracicaba: Alves, $154 \mathrm{p}$.

ICUMSA. 2011. International Commission for Uniform Methods of Sugar Analysis, England: ICUMSA.

LOPES, C.H. 2011. Tecnologia de produção de açúcar de cana, São Carlos: Edufscar. $1^{\mathrm{a}}$ ed. 183p. 
LOPES, C.H.; BORGES, M.T.M.R. 1998.

Produção de açúcar mascavo, rapadura e melado de cana, Porto Alegre: CNA, SEBRAE, SENAR. 44p.

MOSKOWITZ, H.R. 1983. Product testing and sensory evaluation of foods, Westport: Food \& Nutrition. 605p.

SAS. 2003. Statistical Analysis System, Cary: The SAS Institute. Ver.9.1.

STONE, H.S.; SIDEL, J.L. 1985. Sensory evaluation practices, London: Academic. 311p.

VICENTE, A.A. 2000. Preparação de açúcar invertido por meio de invertase imobilizada em sílica. Dissertação (Mestrado) - Instituto de Química, Universidade Estadual Paulista, Araraquara. 